\title{
The Value of Competent Human Advisers
}

\author{
AN AUTOMATED PROCESS "WON'T HELP CLIENTS MANAGE THEIR FEARS"
}

By Tom O'Connor, CFA

I was sorry to see the interview with the CEO of Betterment, Jon Stein, CFA ("Full Auto," March 2016), presented without any commentary or evaluation of Stein's claims. This sort of self-promotion may pass as informative in the popular financial press, but in this magazine, it struck me as unchallenged hyperbole.

Stein says, "The right comparison is not robo-advice versus human advice; it's really robo-advice versus no advice" because "most customers ... are usually coming from a do-it-yourself kind of broker." I agree. But throughout the interview, he compares Betterment's robo-advice with-you guessed ithuman advice. And he uses a conflicted, less-than-diligent human adviser as the straw man for the easiest possible comparison.

Competent human advisers already use extensive automation to continually rebalance (including when cash arrives or leaves), to avoid wash sales, and to harvest tax losses. We have been able to choose from the same universe of investments as Betterment, equally free of conflicts of interest, for decades.

There's nothing new about using low-cost, tax-efficient, globally diversified mutual funds to provide appropriate risk factor exposure so as to target an expected net return at acceptable volatility. Model portfolios have been widely used for many years (not just by Betterment) to ensure that all similarly situated clients experience similar results and to prevent an individual adviser's biases from affecting the advice given to clients.

There's nothing new about developing a very detailed, numerical, repeatable client onboarding process that points to a specific recommendation, so that "if you go through the onboarding questions the same way twice, you'll get the same answer." It is usually not the adviser who "wakes up on the wrong side of the bed" and changes the investment policy but much more often the client. An automated onboarding process won't help clients manage their fears when they propose to selfdestruct by selling risky assets after their values decline.

I was pleased

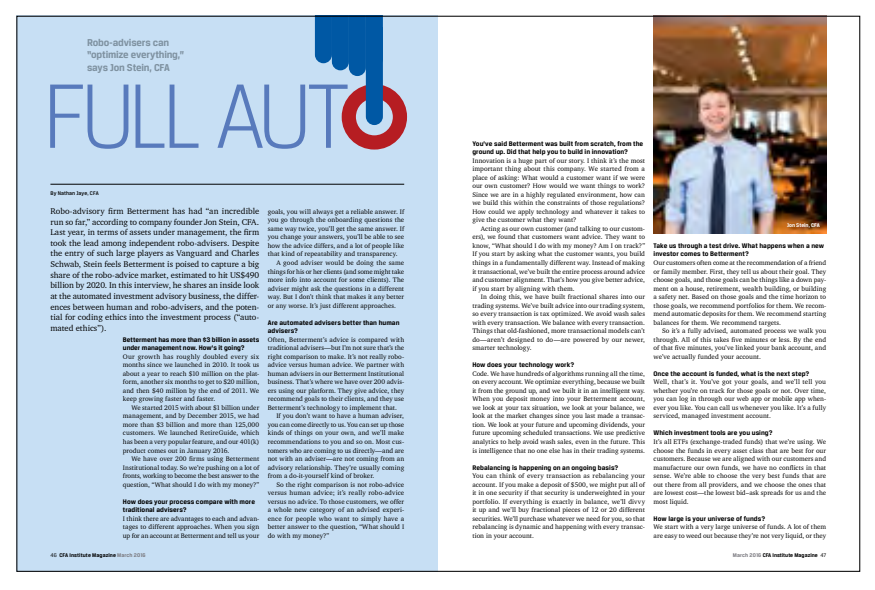
to read about Betterment's automated scanning for future dividends and scheduled transactions to help avoid creating future wash sale situations through today's trading. Although capable humans do this in their trading decisions, automating it is a valuable capability that I have not seen before.

However, Stein's answers to the questions about "robo-ethics" struck me as disingenuous. He states that the question "is not really algorithm versus human" ethics when, in fact, it is. He instead sets the question as algorithm versus conflicted human ethics by asking about the human adviser's financial incentives and then stating that Betterment is "fully aligned with [its] customers" as "a fiduciary and a registered investment adviser" because it charges only "a percentage of assets under management" and doesn't make money on transactions or specific securities. He goes so far as to "challenge the industry to [this] even higher ethical standard."

I can't speak for the industry as a whole, but I have been meeting this standard personally for probably 29 of the 31 years I've been practicing. (The other two years I was an advisory representative of a large insurance company.) Human advisers like me are Betterment's strongest competitors. We actually do more than Betterment, and yes, we charge more. But
[AUTOMATION] DOES NOT ... OCCUPY A HIGHER MORAL GROUND ... THAN COMPETENT HUMAN ADVISERS.

during the entire interview, Stein carefully avoided mentioning us, choosing to attack only the straw man.

I applaud Betterment's incredible automation (including predictive wash sale avoidance). Automating existing best practices brings lower costs to investors, which means more investors can afford an adviser. Automation does not, however, result in better advice than capable humans provide. And it certainly does not allow the automated adviser to occupy a higher moral ground than the competent human advisers whose services it only partially automates.

In this company of peers who pride ourselves on critical analysis, I was dismayed to see a financial services provider given three pages to broadcast so many self-serving claims without a single challenge.

Tom O'Connor, CFA, is a partner in WorthPointe Financial, covering Los Angeles and Orange County, California. 